\title{
Large-Scale Model Testing of High-Speed Railway Subgrade under Freeze-Thaw and Precipitation Conditions
}

\author{
Shasha Zhang $\left(\mathbb{D},{ }^{1}\right.$ Yantao Wang $\left(\mathbb{D},{ }^{1}\right.$ Fei Xiao, ${ }^{1}$ and Weizhi Chen ${ }^{2}$ \\ ${ }^{1}$ School of Highway, Chang'an University, Xi'an 710064, China \\ ${ }^{2}$ China Railway Eryuan Engineering Group CO. LTD., Chengdu 610031, China \\ Correspondence should be addressed to Shasha Zhang; zss_lx@126.com
}

Received 25 April 2019; Revised 27 May 2019; Accepted 10 June 2019; Published 23 June 2019

Academic Editor: Wayne Yu Wang

Copyright ( $\odot 2019$ Shasha Zhang et al. This is an open access article distributed under the Creative Commons Attribution License, which permits unrestricted use, distribution, and reproduction in any medium, provided the original work is properly cited.

To determine whether coarse-grained saline soil meets the deformation requirements of the DY high-speed railway subgrade, a study was conducted by a combination of field-monitoring and laboratory tests. First, several temperature sensors were buried vertically in the ground of a typical section, and the temperature at different depths was monitored for nearly one year and analysed dynamically. It was determined that a depth of $4.8 \mathrm{~m}$ can be set as the constant-temperature layer. Then, based on the field-monitoring results, laboratory tests were carried out on a large-scale subgrade model under freeze-thaw and precipitation conditions. The change of temperature, moisture content, and soil deformation of the subgrade under long-term freeze-thaw and precipitation conditions were obtained. The results show that the temperature changes periodically with a $\mathrm{V}$ shape during the entire cycle. Twenty centimetres below the top surface is the sensitive depth of the sample, and salinity has little effect on temperature change. In the process of cycles, the average moisture content of soils with higher salinity is about $0.5 \%$ lower than that of soils with lower salinity. After nine freeze-thaw cycles, the sample finally shows dissolved settlement deformation. Precipitation mainly affects the deformation of the sample; however, the influence on salt-expansion and frost-heave deformation is less significant. Finally, by predicting the deformation of coarse saline soil, it is proven that the soil can meet the deformation requirements of high-speed railway foundations.

\section{Introduction}

Saline soils are widely distributed worldwide, and natural sulphate saline soils are considered inferior construction materials [1]. With periodic variation of temperature in saline soil, the moisture and salt in the soil migrate, aggregate, crystallise, and dissolve repeatedly, such that the physical and mechanical properties of the saline soil change dramatically [2]. When saline soil is used as the subgrade filler, subgrade diseases, such as salt expansion, frost heave, and collapsibility deformation, will occur under certain conditions. These diseases will seriously affect the stability and durability of the engineering, so saline soil is rarely used in this way. The DY high-speed railway, designed by a Chinese company, needs to pass through coarse-grained saline soil. According to regulations, in the operation of high-speed railway trains, the subgrade line needs high strength, stiffness, long-term stability, and durability of the subgrade material to ensure the longitudinal stiffness of the subgrade and uniform coordination of deformation in the subgrade [3]. Under normal circumstances, well-graded coarse-grained soil has excellent engineering properties, such as good compaction performance, small subsidence deformation, and high bearing capacity, and is usually the preferred material for subgrade filling. There are many wellgraded coarse-grained soils along the line, but their salt content is high. If the coarse-grained saline soil in the area is directly used as the subgrade filler, it may cause salt expansion and frost heave, which in turn may cause uneven deformation of the subgrade and threaten the operation of the high-speed railway. However, if the coarse-grained saline soil along the line is discarded and other soil materials are used, there are other disadvantages, such as high economic costs caused by using imported soil. If some treatment methods are directly adopted, such as predissolving in water, vertical drainage for salt flushing, dynamic compaction, 
blending gravel, and chemical improvement, it will result in a huge economic input [4]. Therefore, in order to meet the stability and durability of the high-speed railway subgrade project and provide better economic benefits, it is necessary to study the engineering characteristics of the coarse-grained saline soil used as the subgrade filler.

Under the influence of the external environment, if the salt expansion, frost heave, and other deformations of the saline soil change only in a small range that satisfies the deformation requirements of the high-speed railway subgrade, then the coarse-grained saline soil can be used as the subgrade filler safely. There are many methods for scholars to study saline soil, such as salt-expansion testing, on-site monitoring, and theoretical calculations [5, 6], and good research results can be achieved. Wu and Zhu [7] carried out the salt-expansion test of coarse-grained sodium sulphate saline soil and designed the coarse-grained soil without salt concentration layers for comparison. The results showed that, under suitable moisture content, the coarse-grained soil containing a salt concentration layer would suddenly undergo destructive salt expansion, whereas that without would not. Wang et al. [8] proposed a generalised thermal conductivity model and used the existing previous literature to evaluate it. The results confirmed that the model was in good agreement. Lai et al. [9] proposed a kinetic model of crystal growth and a simple expression of macroscopic crystal stress. They conducted experiments and confirmed that the model was reasonable and that soil deformation is essentially determined by macroscopic crystal stress. In addition, indoor freeze-thaw cycles are also common research methods for saline soil. The freeze-thaw cycle test can simulate the working conditions and intuitively reflect the changes in temperature, moisture content, and deformation of the saline soil to determine whether the filler meets the engineering requirements. Because of these advantages, the freeze-thaw cycle test has become an effective method for studying saline soil, and some valuable research results have been obtained. Zhang et al. [10] conducted a chemical composition analysis test on the natural coarse-grained saline soil in Xinjiang. Based on this, a large-scale subgrade model test under freeze-thaw cycles was carried out. After multiple freeze-thaw cycles, the maximum salt-expansion rate of the large subgrade surface was only $0.44 \%$, and the natural coarse-grained saline soil could be used for highway subgrade filling. Xiao et al. [11] studied the deformation of $\mathrm{Na}_{2} \mathrm{SO}_{4}$ saline soil under the closed system and freeze-thaw cycles by using the Qinghai-Tibet Plateau silty clay. The results indicated that, in the process of freezing, the soil with higher salt content has a greater effect on frost heaving and salt expansion, whereas the phenomenon of melting and sinking becomes less apparent or even disappears. Zhang et al. [12] conducted a large-scale freeze-thaw cycle shear test. They studied the influence of the number of freeze-thaw cycles on the strength of natural coarse-grained saline soil and obtained the laws of deformation. It is proposed that the migration of water and salt in the soil column profile after multiple freeze-thaw cycles shows incomplete correspondence. Zhang et al. [13] tested high-saturation silty clay and silt under freezing and thawing cycles. The results show that supercooling of both soils occurs early in the freezing process. Under the same conditions, the supercooling temperature and duration of the silty clay are larger than those of silt. In addition, the hysteresis effect of volumetric unfrozen water exists throughout the freeze-thaw cycles. Liu et al. [14] used the comprehensive experimental to study the frost deformation and shear strength increment characteristics of unsaturated soil. At the same time, the influence of soil initial dry density and water content was considered. The results show that the frost shrinkage and soil initial degree of saturation are related. The soil friction angle does not change much when frozen, but the soil cohesion increases a lot due to ice condensation and the increase of capillary cohesion.

The above research has contributed to a better understanding of the engineering properties of coarse-grained saline soil, but there is still a lack of systematic test verification and summary analysis for studying the deformation of the coarse-grained saline soil subgrade under freeze-thaw cycles. Moreover, in model tests, numerical calculations, coupled models, and related studies, the potential effects of rainfall on dissolved settlement and salt-expansion deformation of the saline soil roadbed were not considered. Furthermore, precipitation affects the moisture content of the subgrade soil, and the moisture content will further affect the deformation of the soil. Therefore, if the freeze-thaw cycle test lacks the simulation of precipitation, the results also have certain limitations; thus, it is difficult to apply this test to engineering practice.

In this paper, first, several temperature sensors are inserted from top to bottom in a typical section of the DY high-speed railway. The temperature at different depths was monitored dynamically and analysed for nearly one year. Combined with the temperature data monitored on-site, the temperature range and duration of the indoor model test were determined, and the on-site precipitation was investigated. According to the determined temperature variation range and precipitation, nine freeze-thaw and precipitation cycle model tests were carried out to study the temperature, moisture content, and deformation of the subgrade under the influence of long-term external conditions. The research results can not only provide a reference for the design of this subgrade but also enrich the research system of coarse-grained saline soil and provide a reference for the wide application of infrastructure in saline soil areas.

\section{Project Overview and On-Site Monitoring of Ground}

2.1. Project Overview. The DY high-speed railway project is designed by China Railway Second Institute Engineering Group Co., Ltd. As shown in Figure 1, the start of the DY high-speed railway project is in Tehran, and the end is in Isfahan. Qom is in the middle of the route. The orange lines in Figure 1 represent the route. The site where soil samples were taken is located at pile number $\mathrm{K} 74+000$ which is denoted by the green circle in Figure 1. The whole line is $406 \mathrm{~km}$, the design speed is $300 \mathrm{~km} / \mathrm{h}$, and the postconstruction settlement of the general road section is not greater than $50 \mathrm{~mm}$. A large area of saline-soil desert is 


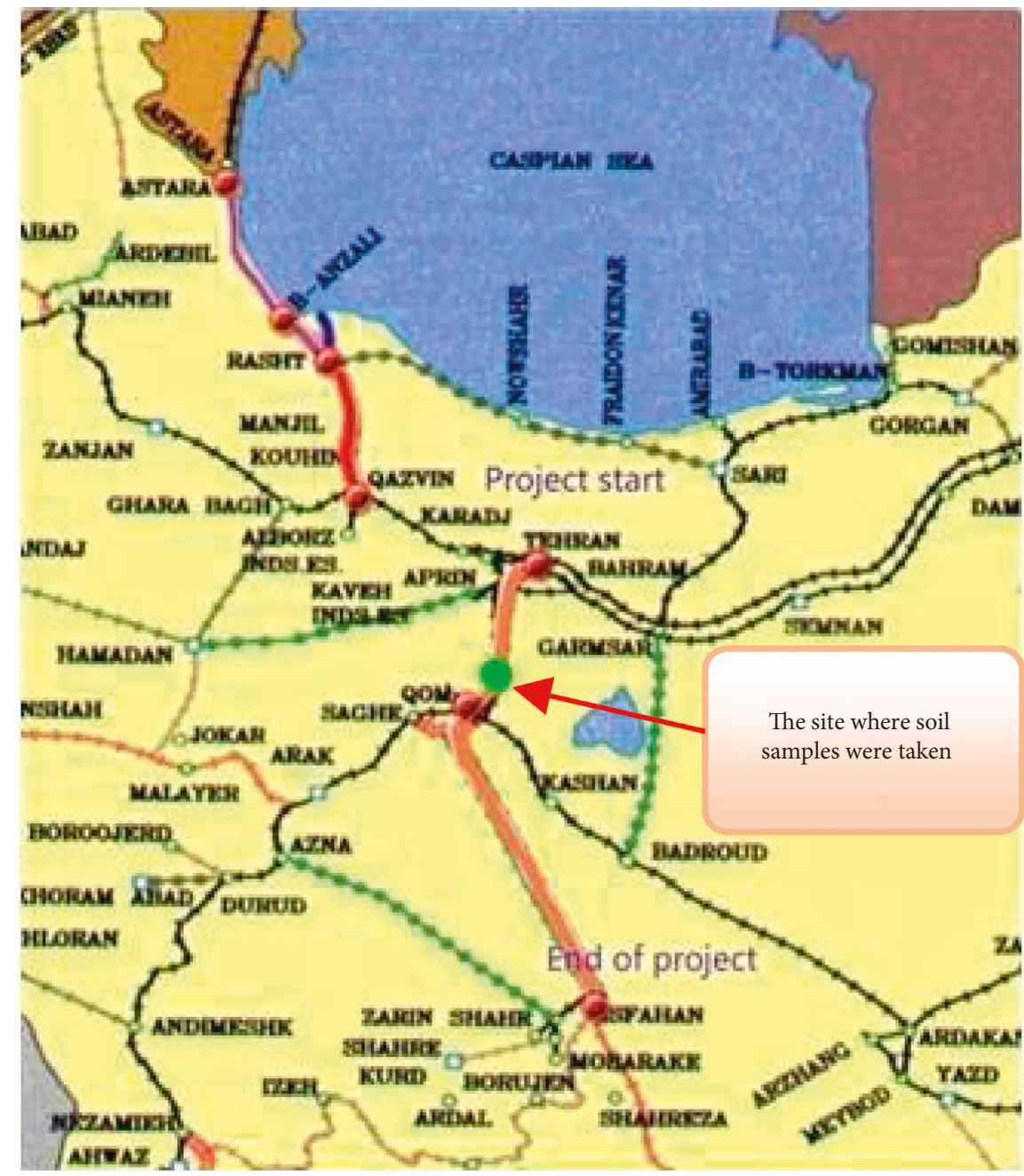

Figure 1: Geological location of the project.

distributed in the area where the test section is located. The terrain is relatively flat, and the landform is singular; there are no other unfavourable geological phenomena in the site. The special geotechnical soil is sulphate saline soil, which is coarse-grained soil. The groundwater level in the test section is low, and the water table is more than $20 \mathrm{~m}$ underground. The area comprises desert and semidesert, and its summer is hot and dry and has little rain. The highest temperature is in July, and the average temperature is greater than $32^{\circ} \mathrm{C}$. The winter, with an average temperature of less than $10^{\circ} \mathrm{C}$ (minimum $-1^{\circ} \mathrm{C}$ and maximum $8^{\circ} \mathrm{C}$ ), is cold and dry, with the lowest temperatures in January. Most of the precipitation in the area occurs between late autumn and spring. There is more winter precipitation than summer, and the annual average precipitation is $100-250 \mathrm{~mm}$. The adopted typical section is located near the salt lake area. There is a large area of saline soil in this section. The terrain is relatively flat, and the landform is single. There is no bad geological phenomenon in the site. The special geotechnical soil is saline soil, which belongs to the sulphate soil. The thickness of the saline soil is greater than $70 \mathrm{~m}$. The groundwater level in the test section is low, and the water level is buried deeper than $20 \mathrm{~m}$.
2.2. Monitoring Design of Ground. The change in ambient temperature is the main factor leading to the salt-expansion deformation of coarse-grained saline soil. Therefore, when the subgrade has not been filled on the site, the temperature sensor is arranged in the ground of the typical section. The monitoring results can clarify the temperature variation characteristics of the coarse-grained saline soil subgrade and provide temperature reference data for the indoor subgrade model test.

The monitoring equipment used in the field test is an MS20-type integrated temperature and moisture sensor, as shown in Figure 2. The sensor is composed of a signal generator and a probe. The sensor shell is made of the $\mathrm{ABS}+\mathrm{PC}$ material. It is added with an anti-UV additive. The dimensional stability is very good. The sensor circuit board is filled with epoxy resin and has good waterproof performance. It has good compression resistance. The sensor has the characteristics of simple installation, high measurement accuracy, and high speed. Based on the FDR mechanism, the sensor can measure the soil moisture and temperature at the same time. The measurement range is a cylinder with a diameter of $10 \mathrm{~cm}$ and a height of $10 \mathrm{~cm}$. In addition, the sensor uses high-frequency excitation signals combined with conductivity compensation technology, so it is also suitable for 


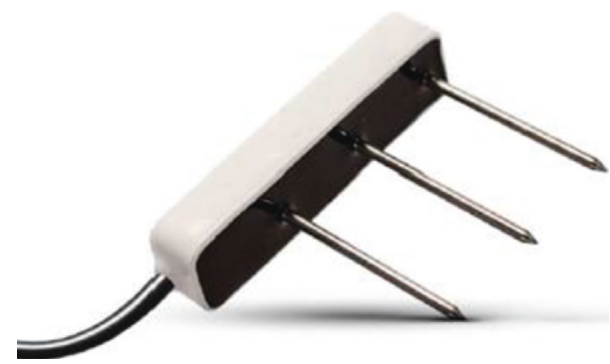

FIGURE 2: MS-20-type integrated temperature and moisture sensor.

measuring soil moisture and temperature in moderately and severely saline-alkali areas. The temperature measurement accuracy of the sensor is $\pm 0.4^{\circ} \mathrm{C}$, and the temperature measurement range is -40 to $80^{\circ} \mathrm{C}$. The moisture measurement accuracy is $\pm 3 \%$, and the measurement range is $0-100 \%$.

According to the temperature distribution characteristics, the temperature sensor is arranged based on the principle of increasing sparsity from top to bottom, and thirteen temperature sensors are buried in the ground. Starting from the top surface, the first three sensors are buried at intervals of $0.1 \mathrm{~m}, 0.3 \mathrm{~m}$, and $0.4 \mathrm{~m}$, and the remaining longitudinal spacing is $0.5 \mathrm{~m}$. The embedding step of the sensor is relatively simple. First, a $5.8 \mathrm{~m}$ deep pit has been dug and the sensor is inserted into the pit wall according to the design scheme. Then, we backfilled the deep pit, and it is shown in Figure 3. Monitoring begins after the temperature sensor is buried. In autumn and winter, the temperature changes greatly, and data are collected once a week. The temperature changes little in summer and remains high, so data are collected every two weeks. The time and ambient temperature are recorded after the data are collected. The specific layout scheme is shown in Figure 4.

\subsection{Analysis and Discussion of Monitoring Results.} Because construction of the subgrade has not yet begun, long-term monitoring of the temperature of the ground is achieved by embedding the sensor in the ground near the subgrade drainage ditch. Figure 5 reflects the variation in soil temperature at different locations within a depth of $5.8 \mathrm{~m}$.

The soil within $1.3 \mathrm{~m}$ of the surface is greatly affected by the change in ambient temperature, and the overall temperature variation trend is similar; this can be roughly divided into three stages. The temperature rises rapidly from mid-April to early June, and then the rate of temperature rise decreases until August, when the temperature reaches its highest level in the year. In the next half-year, the temperature continues to decrease until the temperature reaches its lowest level in February of the following year, whereas the temperature in mid-December slightly rebounded. From February of the following year, the temperature will rise again and another cycle will begin.

Soils within a depth of $1.3-5.8 \mathrm{~m}$ are less affected by ambient temperature, and the temperature fluctuations at different depths are consistent. The temperature fluctuates between $15^{\circ} \mathrm{C}$ and $25^{\circ} \mathrm{C}$. Moreover, in the soil within this range, the temperature tends at the lower section to be higher than that at the upper part, and the maximum and

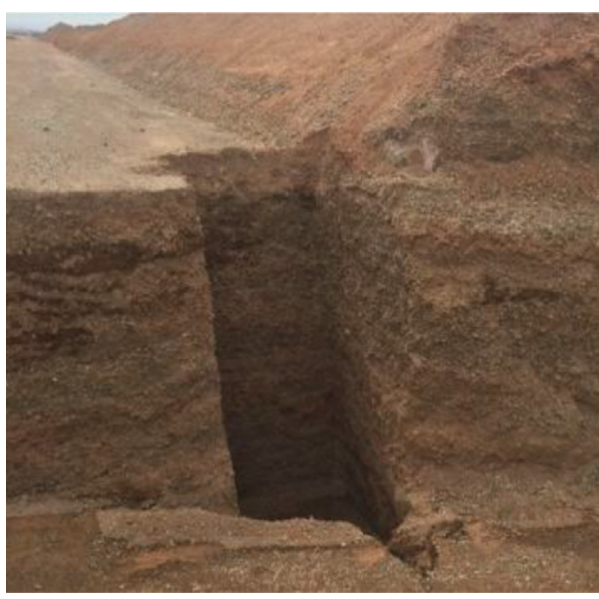

(a)

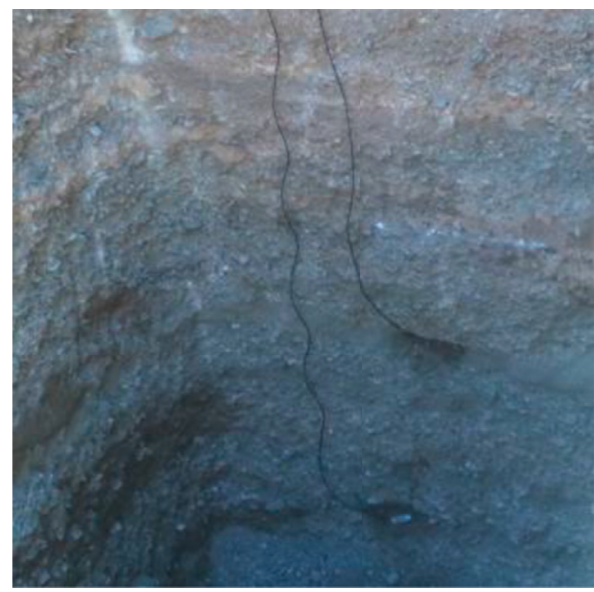

(b)

Figure 3: Sensor burial.

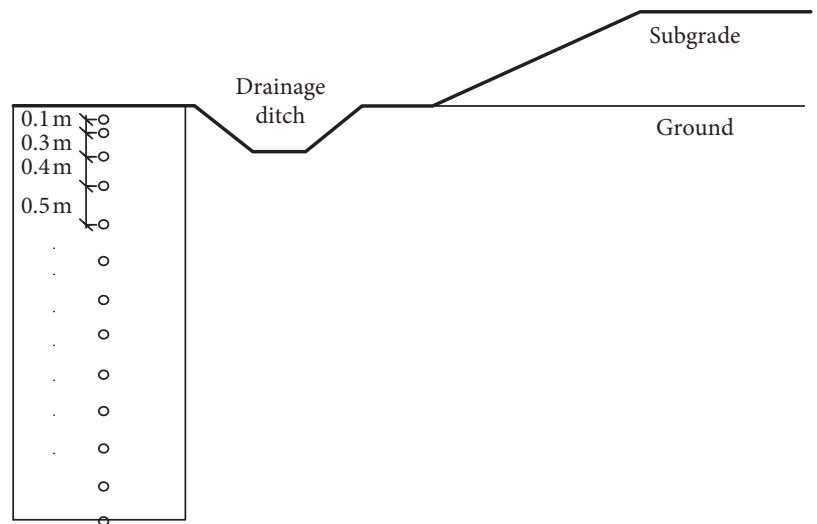

FIgure 4: Typical section sensor layout diagram.

minimum temperatures are generally one month behind the extreme value of the surface temperature. The reason for this hysteresis is mainly that the heat decays from top to bottom, and heat transfer takes a certain amount of time. It can also be seen from Figure 5 that the overall temperature of the soil in the range of depth of $1.3 \mathrm{~m}$ to $5.8 \mathrm{~m}$ is larger than that within $1.3 \mathrm{~m}$ of the surface. This is because the upper soil 


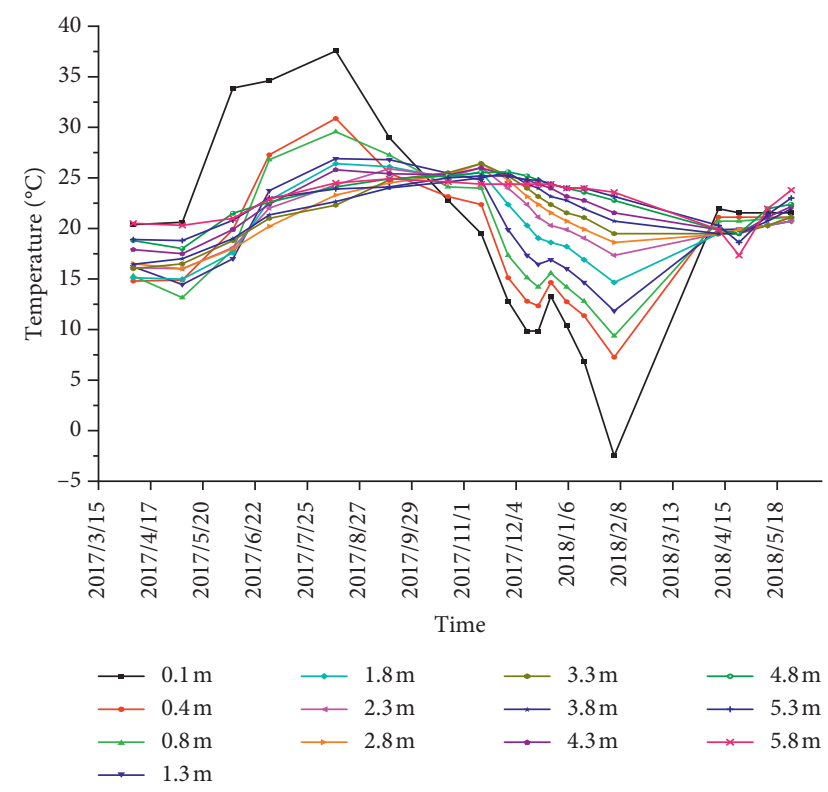

FIGURE 5: Variation in ground temperature with time.

plays a similar function as a cushion that slows down the loss of heat and exerts a heat-preservation effect on the lower soil.

According to previous studies, the salt-expansion and frost-heave amount of the coarse-grained saline soil is increased by a temperature range of -15 to $5^{\circ} \mathrm{C}$ [15]. From the results of on-site temperature monitoring, it can be seen that the ambient temperature of this area has little effect on the salt expansion of the coarse-grained saline soil ground. Figure 6 shows the curve of the maximum temperature difference with depth.

It can be observed that the annual temperature difference has an exponential distribution with depth, and the change process can be divided into three segments. First, within a depth of $1.3 \mathrm{~m}$, the annual temperature difference drops sharply with depth. The condition can easily lead to salt expansion and frost heave. Then, the depth of $1.3-3.8 \mathrm{~m}$ is the transition section, and the annual temperature difference decreases with the increase of depth. Finally, the annual temperature difference tends to be gentle, and the change is small after a depth of $3.8 \mathrm{~m}$. From this trend, it can be seen that the annual temperature difference will inevitably approach $0^{\circ} \mathrm{C}$ below a certain depth, namely, reaching a constant-temperature state. At this time, the temperature change is small, even negligible. It can be seen from Figure 6 that the maximum temperature difference below $4.8 \mathrm{~m}$ is very small, and the temperature change is difficult to discern. Moreover, the overall temperature of the soil below this depth is higher, and the temperature has little effect on the engineering characteristics. Therefore, this depth can be set as the constant-temperature layer of the ground.

\section{Large-Scale Model Test of High-Speed Railway Foundation}

In order to study whether the subgrade meets the requirements of high-speed railways, we conducted a model test. In the

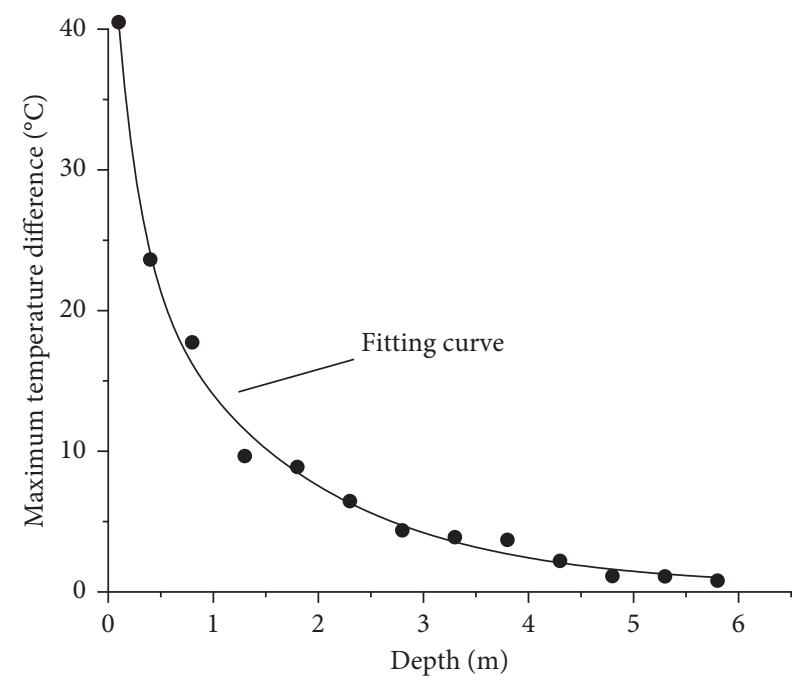

FIGURE 6: Variation of the maximum temperature difference with depth.

process of conducting the test, we consider the factors such as moisture content, temperature, and salinity. Based on the soil samples of the subgrade on-site, we filled the soil sample in proportion to the size and structure of the site. In order to realistically simulate the situation on-site, three compaction levels of the sample from top to bottom, with relative compaction (RC) of $0.97,0.95$, and 0.92 , are considered.

3.1. Test Design. The actual subgrade has a design elevation of $3.6 \mathrm{~m}$, and its roadbed thickness is $2.7 \mathrm{~m}$. Among the roadbeds, the surface and bottom layers of the bed are $0.4 \mathrm{~m}$ and $2.3 \mathrm{~m}$ thick, respectively. The bottom layer of the roadbed comprised $110 \mathrm{~cm}$ of the upper structural layer and $120 \mathrm{~cm}$ of the lower layer. The part below the roadbed is $0.9 \mathrm{~m}$ thick, and the subgrade structure is shown in Figure 7. The compaction of the surface layer of the roadbed is $97 \%$, and the compaction of the bottom layer of the roadbed is $95 \%$. The compaction of the subgrade below the roadbed is $92 \%$.

The ratio of the size of the large-scale subgrade model to the original subgrade is $1: 2.4$, and the model structure is shown in Figure 8. The subgrade consists of the subgrade bed and the embankment. The subgrade bed, which is below the road surface and is the basis of the road surface, bears the weight of the road surface and the traffic load transmitted from the road surface. Furthermore, the embankment is below the subgrade bed, and it is the basis of the subgrade bed. Because of different fillers used in different parts of the subgrade, the principle of layered filling is adopted for filling the sample. The compaction of each part is consistent with that of the original subgrade. The thermal conductivity of sulphate soil is relatively small, generally between 1.0 and 1.8 [16]. The soil column in the middle of the subgrade (the part marked by the red dashed line in Figure 7) is wrapped by the surrounding soil which has a thermal insulation effect on the soil column. Due to the influence of external temperature, a one-dimensional temperature gradient is formed from top 


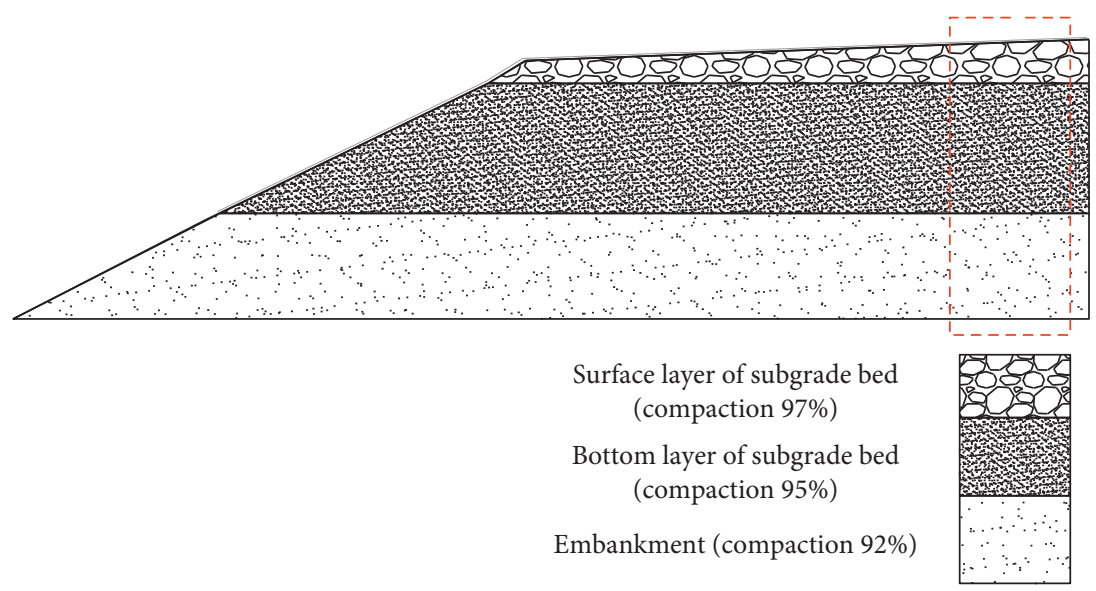

FIGURE 7: Original subgrade structure diagram.

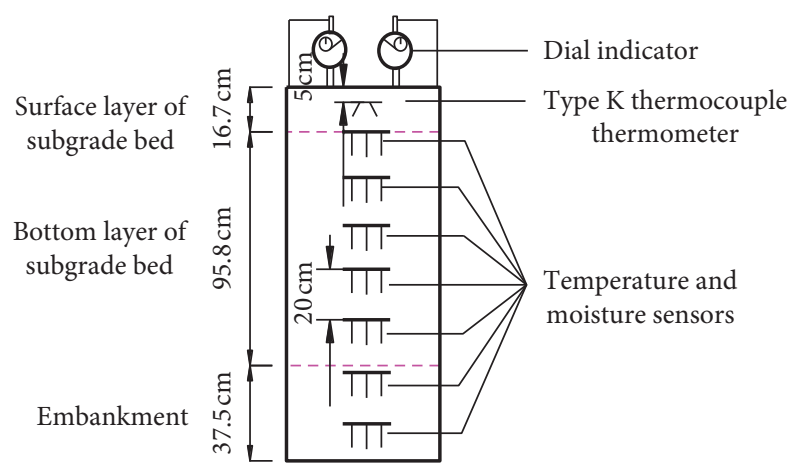

Figure 8: Subgrade model diagram.

to bottom in the soil column. For the accuracy of the model test, when we conduct the model test, the soil column will be wrapped with the insulation material. At the same time, the effect of temperature and precipitation is applied only to the top of the soil column to truly reflect the situation on-site.

3.1.1. Materials. The sulphate saline soil used in the test was obtained from the site of the DY high-speed railway. The basic physical properties of the sulphate saline soil obtained in the laboratory by TB 10102-2010 [17] are shown in Table 1. Based on the particle-grading test analysis, the particle content of the soil sample larger than $60 \mathrm{~mm}$ is less than $15 \%$ and has been eliminated. The soil samples are mainly coarse-grained soil, accounting for $98.58 \%$, which is gravel. The fine particle content is less than $5 \%$, the coefficient of uniformity is greater than $5 \%$, and the curvature coefficient is between 1 and 3. Therefore, it is well graded. According to GB/T50942-2014 [18], the soluble salt content in subgrade fillers is tested. The average soluble salt content in soil samples is shown in Table 2.

The material of the model surface using graded gravel, to which $3 \%$ by weight of cement is added, is consistent with the prototype [19]. The bottom of the bed and subgrade is filled with coarse saline soil, which is divided into two types. One is natural coarse-grained saline soil, called sample 1, and the other contains added sodium sulphate to form coarse-grained saline soil with a soluble salt content of $3 \%$, called sample 2. As discussed by Fang et al. [20], the saturated molar concentration of $\mathrm{Na}_{2} \mathrm{SO}_{4}$ of the two samples is $1.33 \mathrm{~mol} / \mathrm{L}$. But the initial molar concentration of $\mathrm{Na}_{2} \mathrm{SO}_{4}$ of sample 1 is $0.953 \mathrm{~mol} / \mathrm{L}$ and that of sample 2 is $1.198 \mathrm{~mol} / \mathrm{L}$. So the initial molar concentrations of $\mathrm{Na}_{2} \mathrm{SO}_{4}$ of the two samples are much smaller than $1.33 \mathrm{~mol} / \mathrm{L}$.

3.1.2. Test Instrument. The model is filled in layers, and the compaction thickness of each layer is controlled at $5 \mathrm{~cm}$. A K-type thermocouple thermometer is buried at a depth of $5 \mathrm{~cm}$, and the surface temperature changes and the heating and cooling effects of the thermostatic bath are monitored. Then, MS-20-type temperature and moisture sensors were installed at a depth of 20, 40, 60, 80, 100, 120, and $140 \mathrm{~cm}$.

3.1.3. Test Apparatus and Procedure. The test apparatus is shown in the schematic diagram in Figure 9. The soil sample is placed in a plexiglass tube (Figure 10(a)), and the temperature is controlled by a cooling head (Figure 10(b)) linked by a thermostatic bath (DC-3015-type cryostat) (Figure 10(c)). In order to make the boundary conditions of the sample similar to the actual working conditions, an insulation material is wrapped around the test tube to 
TABle 1: Physical properties of the soil.

\begin{tabular}{|c|c|c|c|c|c|c|c|}
\hline \multirow{2}{*}{ Dry density $\left(\mathrm{g} / \mathrm{cm}^{3}\right)$} & \multicolumn{3}{|c|}{ Particle composition (\%) } & \multirow{2}{*}{$\begin{array}{l}\text { Maximum dry } \\
\text { density }\left(\mathrm{g} / \mathrm{cm}^{3}\right)\end{array}$} & \multirow{2}{*}{$\begin{array}{c}\text { Optimum water } \\
\text { content }(\%)\end{array}$} & \multirow{2}{*}{$\begin{array}{c}\text { Coefficient of } \\
\text { uniformity (\%) }\end{array}$} & \multirow{2}{*}{$\begin{array}{l}\text { Coefficient of } \\
\text { curvature (\%) }\end{array}$} \\
\hline & $2-60 \mathrm{~mm}$ & $0.075-2 \mathrm{~mm}$ & $<0.075 \mathrm{~mm}$ & & & & \\
\hline 2.21 & 76.50 & 22.08 & 1.42 & 2.21 & 7.6 & 47.6 & 2.7 \\
\hline
\end{tabular}

Table 2: Soluble salt content in soil.

\begin{tabular}{lccccc}
\hline \multicolumn{3}{c}{ Negative ions (\%) } & \multicolumn{2}{c}{ Positive } & Tons (\%) \\
$\mathrm{HCO}_{3}{ }^{-}$ & $\mathrm{SO}_{4}{ }^{2-}$ & $\mathrm{Cl}^{-}$ & $\mathrm{Ca}^{2+}$ & $\mathrm{Mg}^{2+}$ & content (\%) \\
\hline 0.0115 & 0.042 & 0.693 & 0.282 & 0.003 & 1.486 \\
\hline
\end{tabular}

prevent heat exchange between the sample and the surrounding environment.

According to the measured data during late autumn and the following early spring, from October 2017 to April 2018, the highest temperature appeared in October, reaching $26.9^{\circ} \mathrm{C}$, and the lowest temperature appeared in February, reaching $-3.8^{\circ} \mathrm{C}$. The monthly average temperature change is $3-6^{\circ} \mathrm{C}$. Therefore, the temperature change interval set in the indoor test was from $+30^{\circ} \mathrm{C}$ to $-5^{\circ} \mathrm{C}$, and the temperature gradient was $5^{\circ} \mathrm{C}$. The cooling regime was $30^{\circ} \mathrm{C} \longrightarrow 25^{\circ} \mathrm{C} \longrightarrow 20^{\circ} \mathrm{C} \longrightarrow 15^{\circ} \mathrm{C}$ $\longrightarrow 10^{\circ} \mathrm{C} \longrightarrow 5^{\circ} \mathrm{C} \longrightarrow 0^{\circ} \mathrm{C} \longrightarrow-5^{\circ} \mathrm{C}$. Each stage lasted for $2 \mathrm{~h}$. This temperature was maintained for at least $12 \mathrm{~h}$ when the temperature reaches $-5^{\circ} \mathrm{C}$. After the reading became stable, the low-temperature bath was turned off and cooling was stopped. The heating process adopts the method of natural warming. The natural warming process lasted for at least $12 \mathrm{~h}$, and precipitation was simulated when the temperature rose to approximately $10^{\circ} \mathrm{C}$. The self-made perforated plate (Figure 10(d)) was used to replace the cooling head to simulate precipitation. $784.2 \mathrm{~cm}^{3}$ water should be added to the sample one time (Figure 11) according to calculations from the meteorological data by the following equation:

$$
V=\frac{H \times \pi \times D^{2}}{4},
$$

where $V$ is the water volume, $H$ is the maximum rainfall in 2018 (it was originally $2.7 \mathrm{~cm}$, but by scale $1: 2.4$ conversion, it was $1.125 \mathrm{~cm}$ ), and $D$ is the diameter of the plexiglass tube $(29.8 \mathrm{~cm})$. We know that some of the precipitation in the actual subgrade will be discharged into the drain, and it is impossible to completely infiltrate the subgrade. Adding water at once instead of adding water evenly at a certain flow rate is to simulate the worst conditions. During the whole freeze-thaw and precipitation cycles, the cooling process lasted for $26 \mathrm{~h}$ and the natural heating process lasted for $12 \mathrm{~h}$. One cycle lasted for $38 \mathrm{~h}$, and there were nine cycles. The soil deformation is monitored by a dial gauge (accuracy $0.01 \mathrm{~mm}$ ) mounted on the cooling head or perforated plate. The data of temperature and moisture are automatically collected by the instrument. For the dial indicator, the data are collected every two hours during the cooling phase, stopping collection at $-5^{\circ} \mathrm{C}$. The data in the early phase of warming ( $26 \mathrm{~h}$ to $32 \mathrm{~h}$ of each cycle) were collected once every $2 \mathrm{~h}$ and then collected once $1 \mathrm{~h}$ later.

\subsection{Results and Discussion}

3.2.1. Temperature Profile. During the test, the soil temperature changes in different parts of the subgrade model are shown in Figure 12.

It can be seen from Figure 12 that the temperature variation characteristics of soils with different salt contents were similar, indicating that the salt content has limited effect on the temperature change in the soil. During the entire freeze-thaw and precipitation cycles, the soils at different depths showed significant differences in characteristics. The temperature change was the largest at a depth of $5 \mathrm{~cm}$, and the lowest temperature is basically between -5 and $5^{\circ} \mathrm{C}$. With periodic changes in the temperature increase and decrease, the curve exhibits a periodic change in a zigzag pattern. At a depth of $20 \mathrm{~cm}$, the change amplitude of temperature instantaneously decreases to approximately $1 / 3$ of the depth of $5 \mathrm{~cm}$, and the lowest temperature is concentrated between 15 and $20^{\circ} \mathrm{C}$. It also changes periodically with a $\mathrm{V}$ shape, but the time when the extreme value occurs shows a significant lag. Similarly, at depths of $40 \mathrm{~cm}$ and $60 \mathrm{~cm}$, the magnitude of the temperature change is also successively decreased, and the extreme values are successively delayed, as well. The temperature variation below $60 \mathrm{~cm}$ is not obvious. The cooling rate and time when the temperature extreme value appears are close, and the soil temperature remains essentially stable. This indicates that the soil above $60 \mathrm{~cm}$ in depth is more active to the natural temperature change than that below $60 \mathrm{~cm}$, and the thermal effect of the shallow soil changes drastically. The magnitude of the temperature difference decreases as the sample depth increases; that is, the change in thermal effect in the soil decreases with depth [6].

In general, the soil temperature rises with increasing depth, and the internal temperature change in the soil lags behind the external environment temperature. As the depth of the soil increases, the temperature variation of the soil decreases, and the temperature hysteresis effect becomes more obvious. There are two main reasons for these phenomena. On the one hand, the soil is exposed to the external environment for a long time, and the shallower part is affected by the external environment temperature for a long time. Its temperature variation range and temperature change rate are relatively large. On the other hand, in the temperature-increase phase, as the depth of the soil increases, the heat gradually decreases and the rate of temperature increase gradually becomes smaller. In the temperature-cooling stage, the upper soil has a certain thermal insulation effect on the lower soil. This causes the soil temperature to decrease at a lower rate, and the lower soil temperature tends to be higher than that of the upper soil. In addition, the rate of heating is always slightly greater than the rate of cooling. 


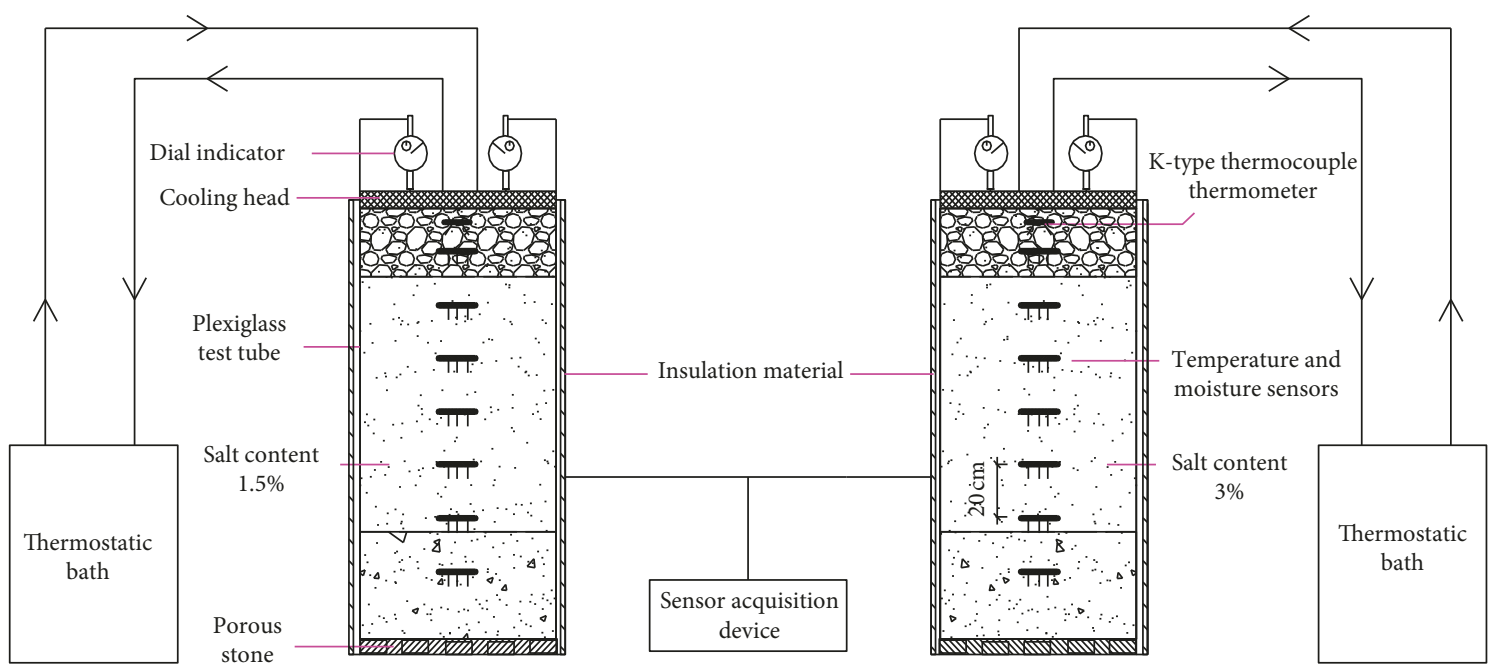

Surface layer of subgrade bed

Bottom layer of subgrade bed

Embankment

Figure 9: A schematic diagram of the experimental equipment.

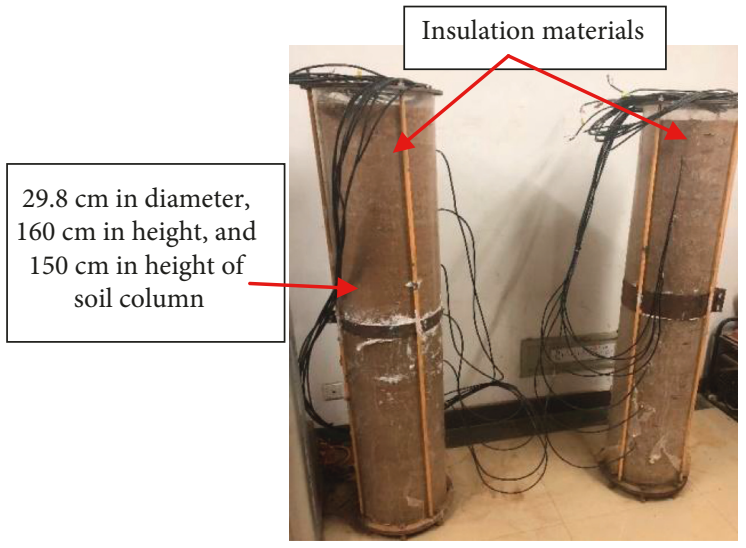

(a)

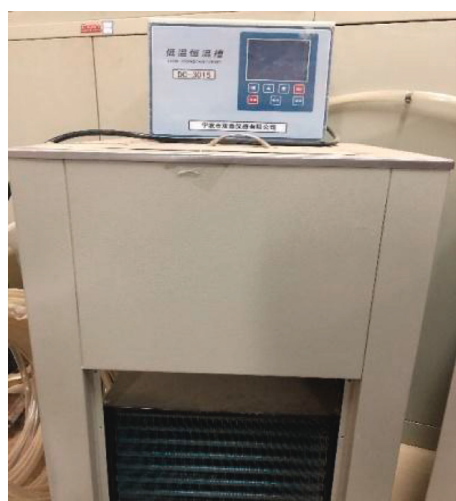

(c)

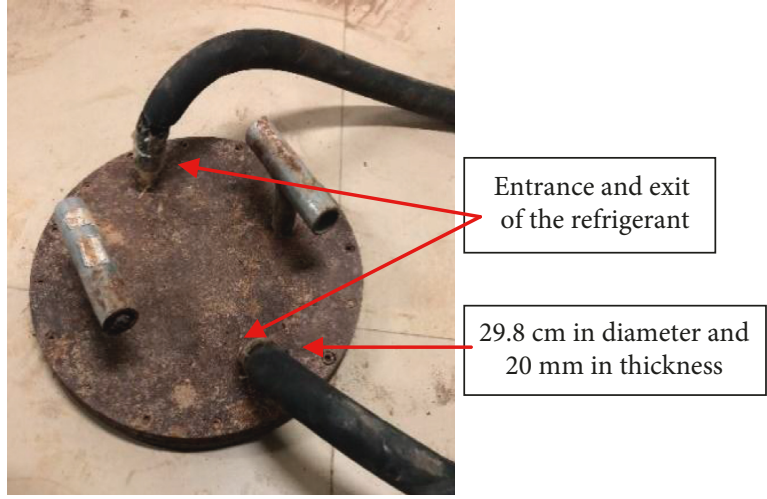

(b)

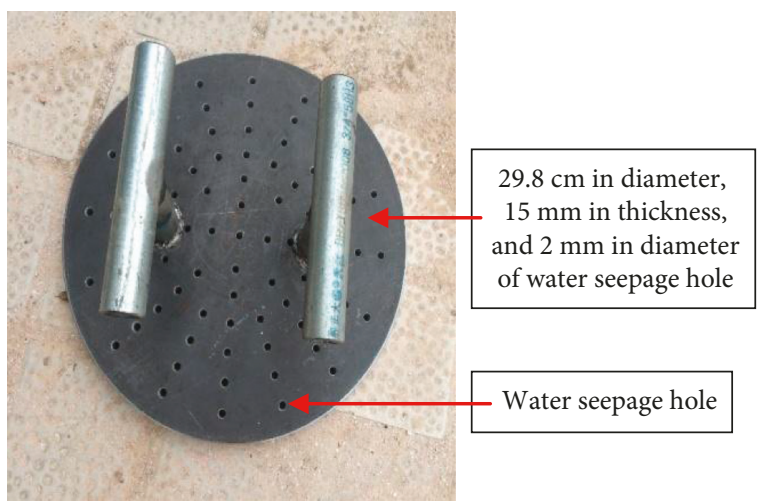

(d)

Figure 10: Diagram of the test equipment. (a) Plexiglass tube. (b) Cooling head. (c) Thermostatic bath. (d) Perforated plate.

The temperature change range of soil at depths of $5 \mathrm{~cm}$, $20 \mathrm{~cm}$, and $40 \mathrm{~cm}$ is, respectively, -5.5 to $27.5^{\circ} \mathrm{C}, 19.5$ to $27.3^{\circ} \mathrm{C}$, and 23.8 to $28.5^{\circ} \mathrm{C}$. The soil temperature fluctuation below $60 \mathrm{~cm}$ is small, and the variation range is between $27.3^{\circ} \mathrm{C}$ and $29.5^{\circ} \mathrm{C}$. The solubility of sodium sulphate at $32.4^{\circ} \mathrm{C}$ peaks, and the solubility will decrease above or below $32.4^{\circ} \mathrm{C}$. The salt-expansion and frost-heave amount of the coarse-grained saline soil increases strongly within a 


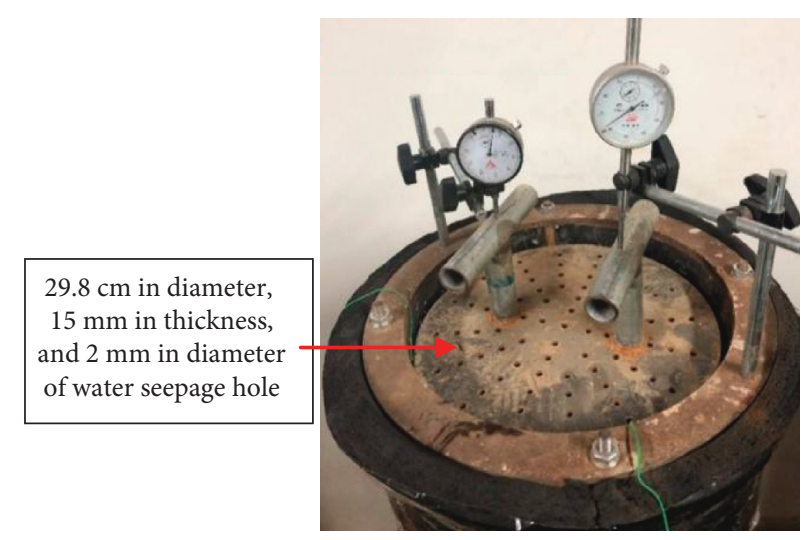

(a)

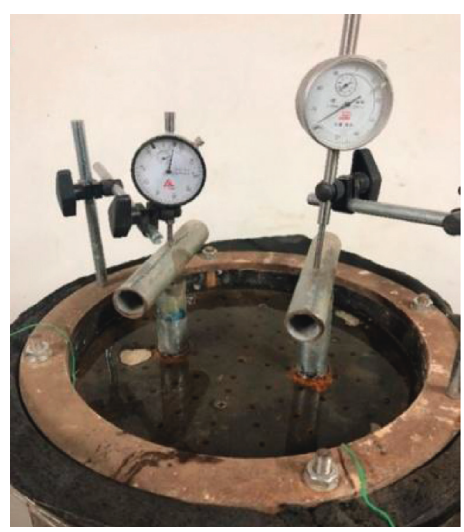

(b)

Figure 11: Diagram of simulating precipitation. (a) Before adding water. (b) After adding water.

temperature range of -15 to $5^{\circ} \mathrm{C}$, which accounts for more than $70 \%$ of the total salt expansion and frost heave. Therefore, the sensitive depth of soil affected by temperature is within $20 \mathrm{~cm}$ of the top surface. The depth by conversion is similar to the temperature-monitoring result on-site.

3.2.2. Moisture Distribution Profile. The curves of the moisture content with time are shown in Figure 13.

As can be observed from Figure 13, varying salt content has a significant impact on the soil moisture content. The moisture content of sample 1 changed greatly, and the moisture content distribution of sample 1 was more dispersed than that of sample 2, changing from $8.5 \%$ to $10.5 \%$. The moisture content of sample 2 changes from $8.5 \%$ to $10 \%$, and the moisture content distribution is concentrated by comparison. From Figures 13(a)-13(g), we can draw that the moisture content of the soil sample at the depth from $20 \mathrm{~cm}$ to $60 \mathrm{~cm}$ has a significant periodicity as time goes on. However, the moisture content of the soil sample at the depth from $80 \mathrm{~cm}$ to $140 \mathrm{~cm}$ does not have. We also can draw that the moisture content of sample 2 at the depth from $20 \mathrm{~cm}$ to $120 \mathrm{~cm}$ always changes as time goes on. The moisture content of sample 2 at $140 \mathrm{~cm}$ depth is basically kept at a horizontal line, approximately 9.5\%. But, the moisture content of sample 2 below $80 \mathrm{~cm}$ is basically kept at a horizontal line, approximately $9.3 \%$. As seen from Figure 13(a), the moisture content of sample 2 at the $20 \mathrm{~cm}$ depth is higher than that of sample 1. As seen from Figures 13(b) and 13(c), the moisture content of sample 1 at the depth from $40 \mathrm{~cm}$ to $60 \mathrm{~cm}$ is higher than that of sample 2 . As seen from Figures 13(d)-13(g), the moisture content of sample 2 below $60 \mathrm{~cm}$ is always higher than that of sample 1 .

We know that there are temperature gradients, gravity field, and hydraulic gradient in the soil sample. Water will continuously infiltrate under the action of gravity field. As discussed by Deng et al. [21], because the salt blocked the voids in the soil, the permeability coefficient of the soil is lowered. So after simulating precipitation at the top of the soil sample, sample 2 has the higher moisture content at the $20 \mathrm{~cm}$ depth. As seen from Figures 13(b) and 13(c), at the beginning, the moisture content of sample 2 is higher than that of sample
1 at the depth from $40 \mathrm{~cm}$ to $60 \mathrm{~cm}$. However, part of the water was evaporated because of slow water infiltration. Then, the moisture content of sample 1 at the depth from $40 \mathrm{~cm}$ to $60 \mathrm{~cm}$ is higher than that of sample 2 . Because the water in lower salt content infiltrated fast, the moisture content of sample 2 is always higher than that of sample 1 below the $60 \mathrm{~cm}$ depth. From Figures 13(a)-13(g), we can draw that the moisture content of the soil sample at the depth from $20 \mathrm{~cm}$ to $60 \mathrm{~cm}$ has a significant periodicity as time goes on. Also, we can draw that the test conditions mainly affected the soil within the $60 \mathrm{~cm}$ depth of the soil sample. As seen from Figure 13(a), the moisture content generally increased first and then decreased with time. It is because we simulated precipitation in each freeze-thaw cycle. In the first few freezethaw cycles, the water content increased gradually due to simulated precipitation. After that, the soil sample reached saturation and the water infiltration rate slowed down. Under the influence of evaporation, the water content began to gradually decrease in the next few cycles.

\subsubsection{Curves of Deformation. Figures 14 and 15 present} graphs showing the salt-expansion and frost-heave deformation of the coarse-grained saline subgrade model with different salt contents under multiple freeze-thaw and precipitation cycles.

For sample 1, because the deformation does not fully revert when the temperature rises, the soil produces salt expansion during the first freeze-thaw and precipitation cycle. The amount of collapse during the second cycle is greater than the amount of salt expansion, so the sample produces a collapsibility deformation. The third period of soil temperature deformation is also small. During the third cycle, when cooling, the amount of collapsibility deformation has increased dramatically. There are two reasons for this phenomenon. One is that the salt with the water migrates to the cold end, so the salt content of the upper soil increases and the salt expansion increases. Another reason is that the moisture content of the sample increases as the precipitation accumulates, so the amount of frost heave increases. From the beginning of the fourth cycle, the deformation fall of the soil shows a reduction in the fold line 


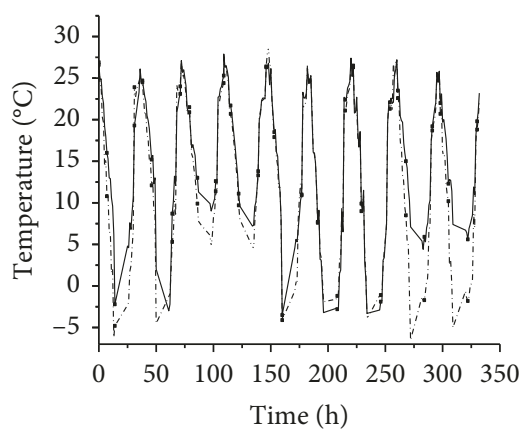

$\rightarrow 5 \mathrm{~cm}$ of sample 1

-. $5 \mathrm{~cm}$ of sample 2

(a)

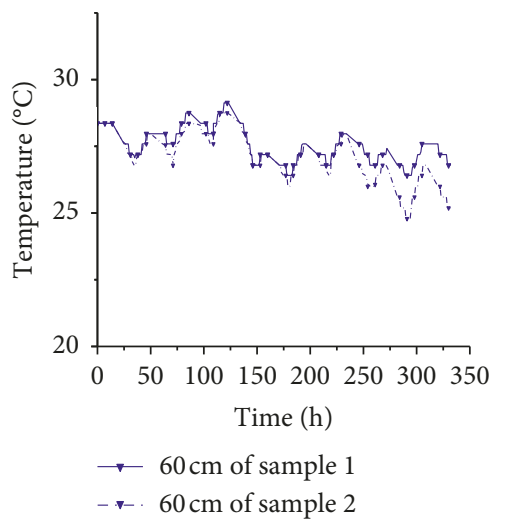

(d)

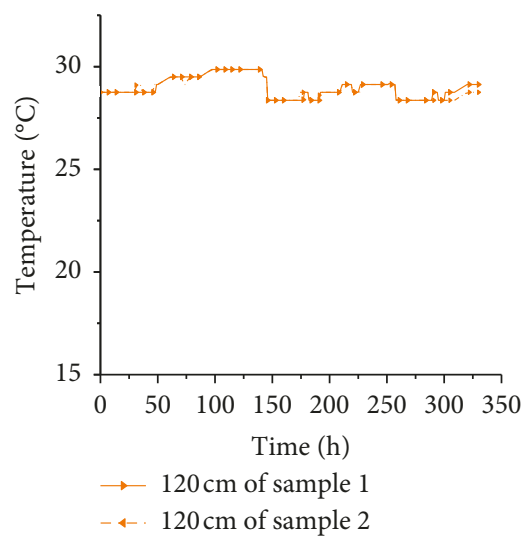

(g)

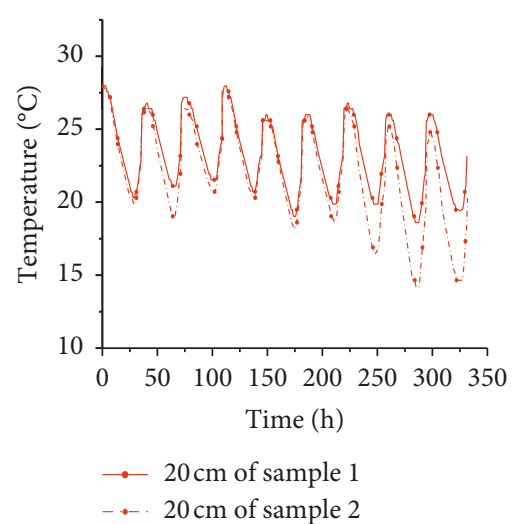

(b)

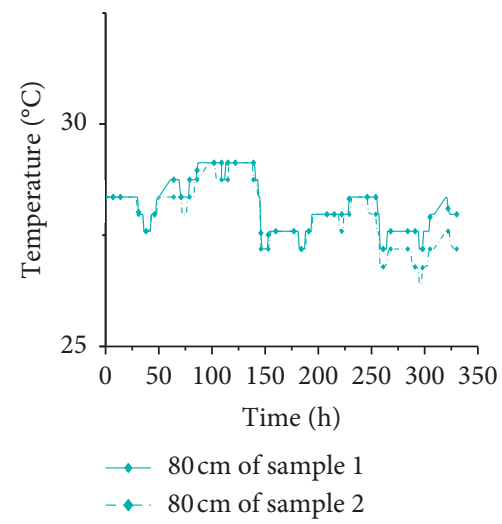

(e)

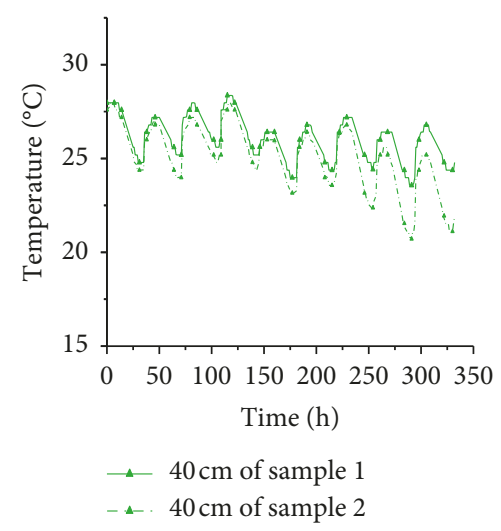

(c)

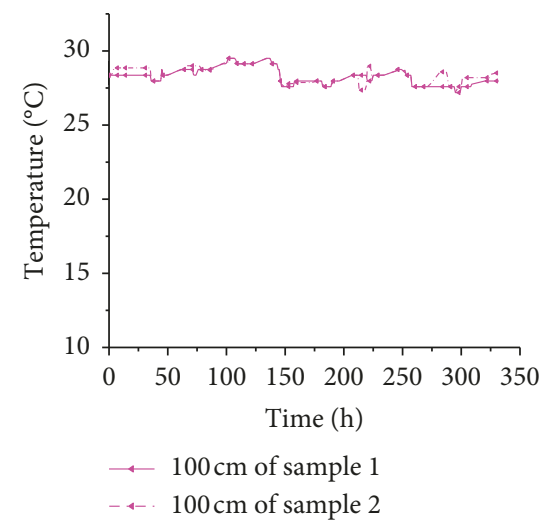

(f)

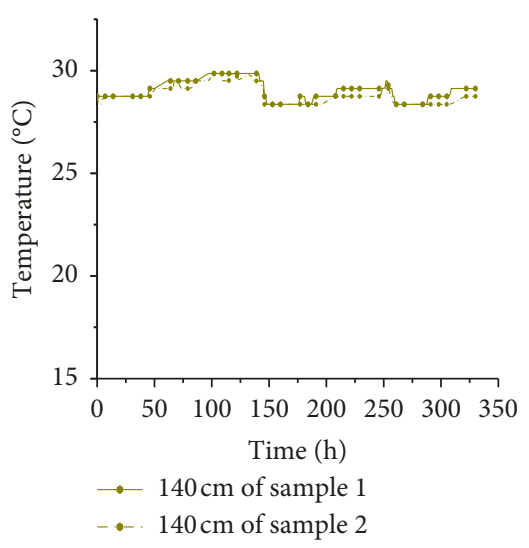

(h)

FIgURE 12: Typical curves of the measured temperature with time for sample 1 of $1.5 \%$ salt content and sample 2 of $3 \%$ salt content.

during the heating phase. The amount of sudden deformation recovery at one time is large, and the deformation recovers after a very slow recovery period. The final deformation gradually recovers. As the temperature rises, the collapse suddenly becomes large, and then the recovery speed is very slow for a while. After that, the amount of deformation falls back greatly once again, and then the deformation gradually recovers. It can be seen that although there is salt expansion at this time, frost-heave deformation plays a leading role. As the test progresses, the collapsibility deformation of the soil shows accumulation, and the final settlement of the sample reaches $0.63 \mathrm{~mm}$.
The deformation of sample 2 in the first cycle is higher than that of sample 1 at the same stage, which can further prove that the deformation of the soil at this stage is mainly salt expansion. At the second and third cycles, the phenomenon of collapse began to occur. The amount of collapse of sample 2 was less than that of sample 1 at the same stage. This is because the soil with higher salinity has a small permeability coefficient and the infiltration rate is slow after precipitation. Like sample 1, the deformation also increased dramatically since the fourth cycle began. However, the deformation that lagged after heating did not recover immediately as in sample 1. After the temperature rise, the 


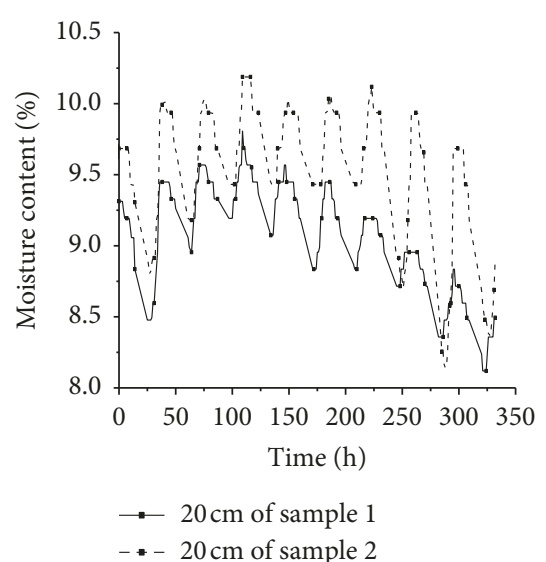

(a)

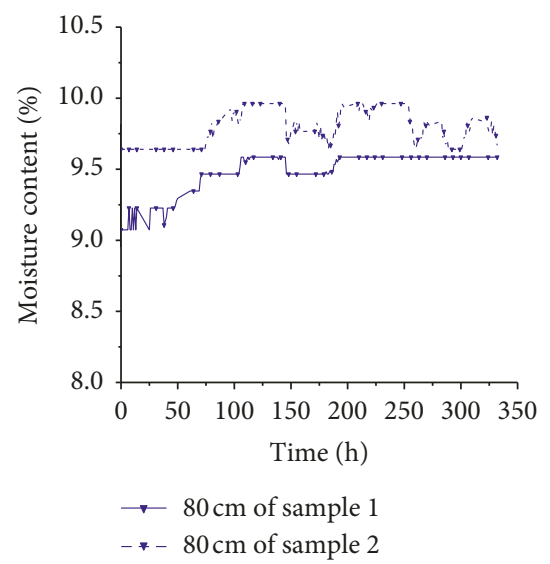

(d)

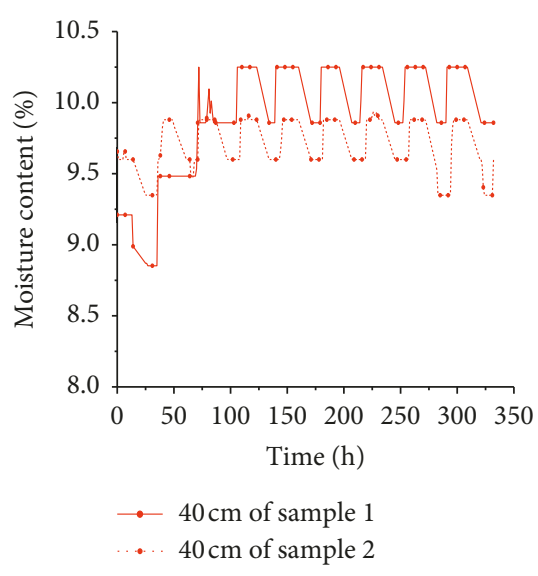

(b)

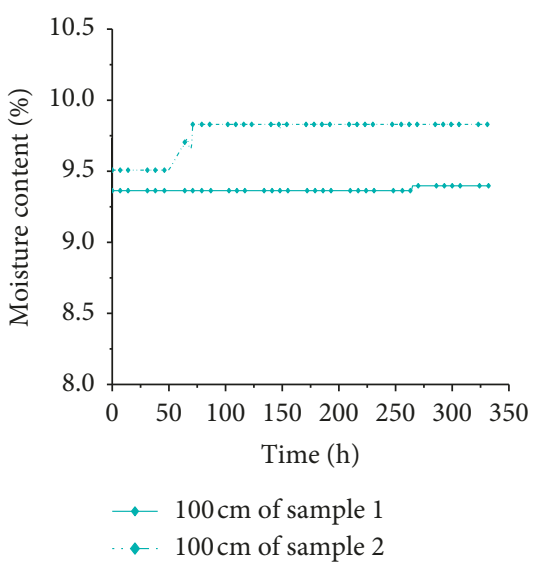

(e)

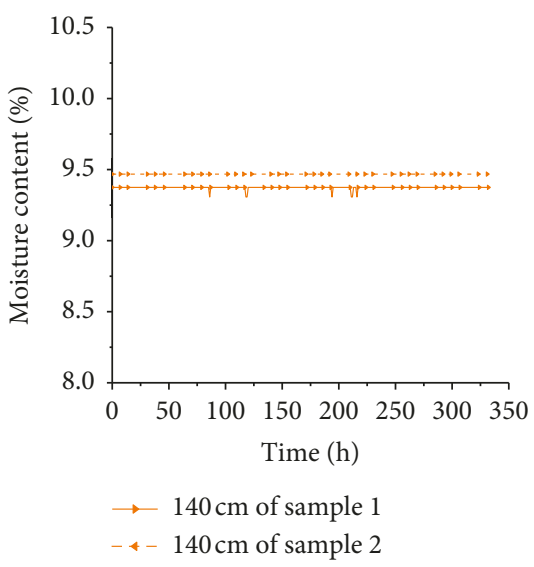

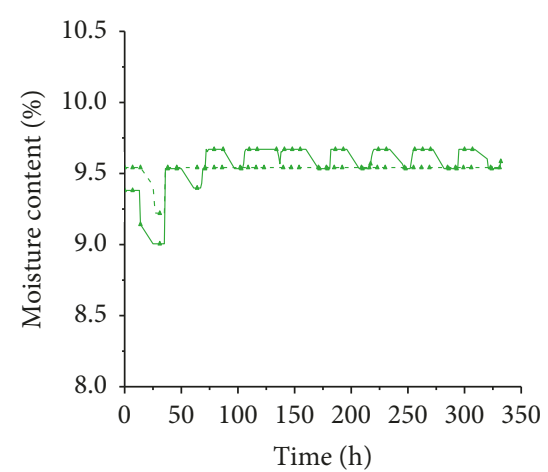

$\triangle 60 \mathrm{~cm}$ of sample 1

$-\star-60 \mathrm{~cm}$ of sample 2

(c)

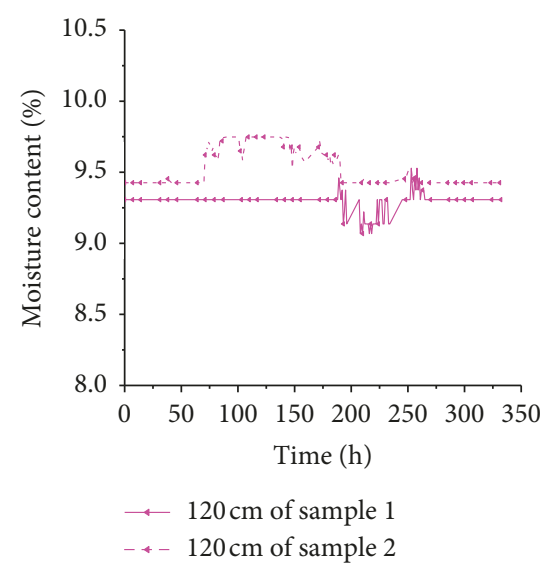

(f)

(g)

Figure 13: Curves of the moisture content with time for sample 1 of $1.5 \%$ salt content and sample 2 of $3 \%$ salt content.

recovery of the deformation amount is also relatively gentle, and the fold line reduction is not obvious. This indicates that salt has the effect of inhibiting frost heaving in the soil.

It can be seen from Figures 14 and 15 that the deformation process of coarse-grained saline soil can be divided into four stages. In the initial stage of cooling, there is no obvious deformation before the temperature drops to $5^{\circ} \mathrm{C}$. Obvious salt-expansion deformation occurs when the temperature drops below $5^{\circ} \mathrm{C}$. Then, the amount of salt- expansion and frost-heave deformation continues to increase with temperature at $-5^{\circ} \mathrm{C}$. During the natural warming phase, the crystallised water in the soil melts, and the salt-expansion and frost-heave deformation recovers. The collapsibility deformation occurs at the same time. It can be seen that, during the freeze-thaw and precipitation cycles, the deformation of coarse-grained saline soil is mainly saltexpansion deformation, frost-heave deformation, and collapsibility deformation, and it finally shows the settlement of 


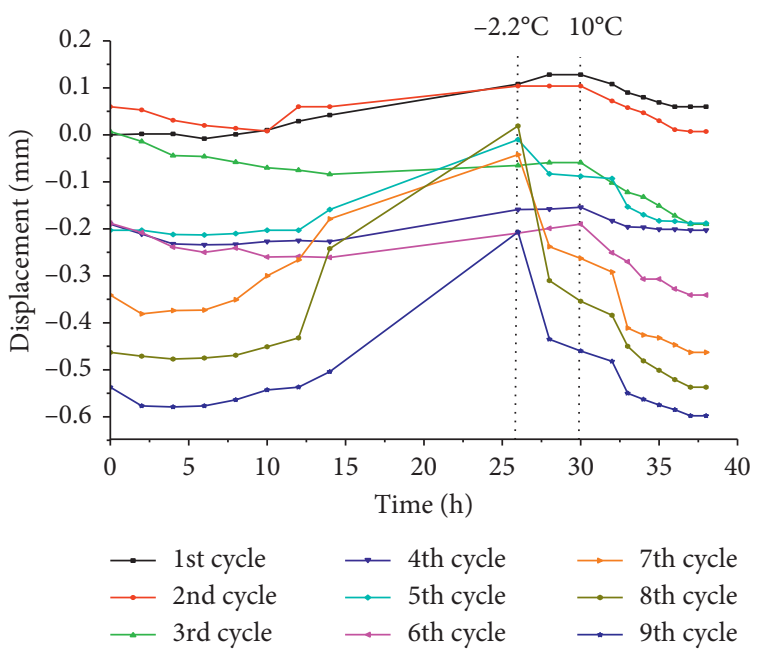

(a)

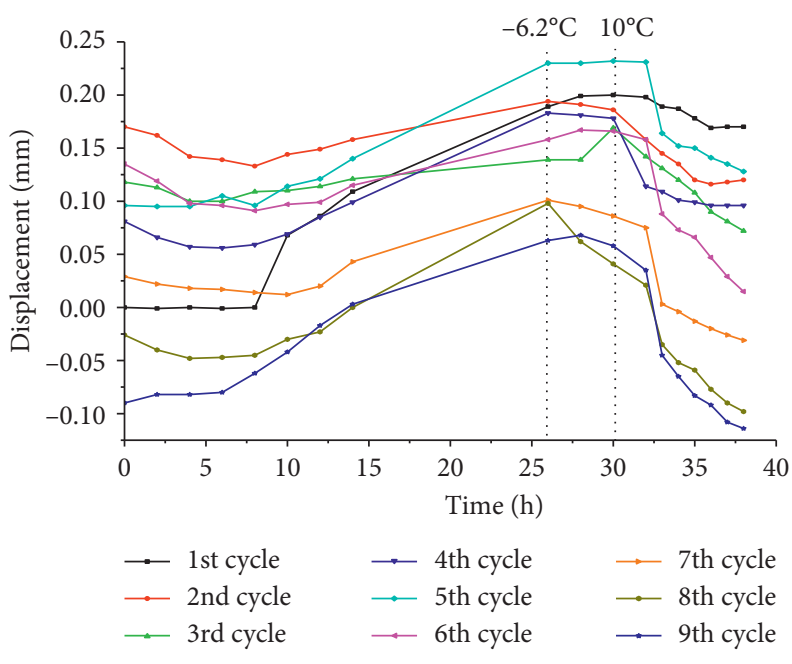

(b)

Figure 14: Curves of the deformation with time for (a) $1.5 \%$ salt content and (b) $3 \%$ salt content.

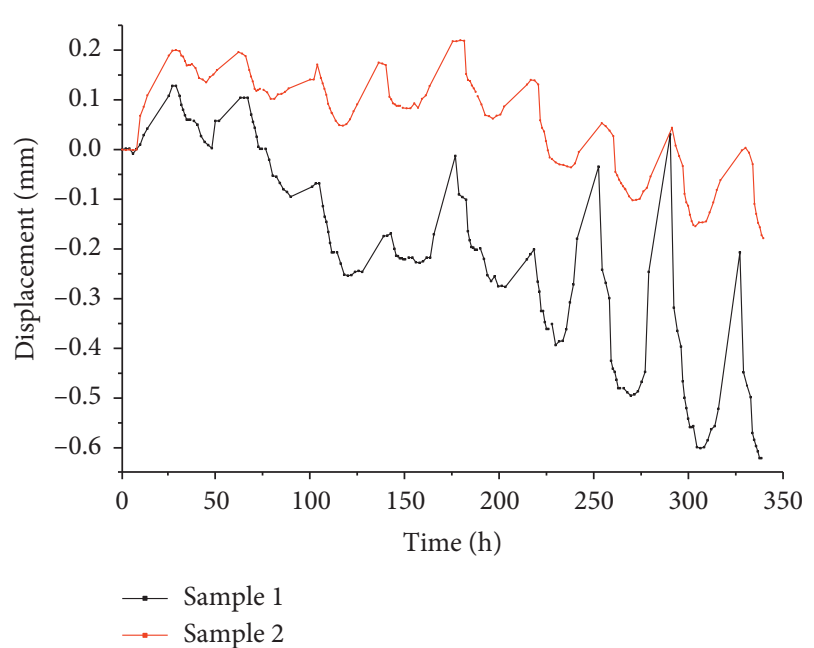

Figure 15: Curves of the total deformation with time for sample 1 and sample 2 .

the subgrade model. The specific reason is that, at the initial stage of cooling, the amount of salt expansion is small. Due to the presence of more pores in the coarse-grained saline soil, the salt expansion can be absorbed such that no significant deformation is realised. After the temperature drops below $5^{\circ} \mathrm{C}$, because the pores are almost filled, significant deformation begins to occur. When the temperature is maintained at $-5^{\circ} \mathrm{C}$, the salt expansion and the frost heave occur simultaneously, so the amount of deformation continues increasing. The deformations cause damage to the soil structure [15]. During the natural warming phase, the crystalline salt of the saline soil begins to dissolve, and each sodium sulphate crystalline molecule will release 10 water molecules. The volume of the crystalline salt is reduced, and the damaged soil begins to sink without support. In addition, the crystalline salt releases water molecules due to increasing temperature. The water dissolves some other crystalline salts, which are cemented with the soil particles and act together as a skeleton to cause the destruction of the bonded structure in the soil. The pores filled with salt lack stability and collapse under a certain load, thereby destroying the structure of the soil and reducing its strength. The soil particles are rearranged and cause collapse because of the absence of large pores. Repeatedly, the crystallisation and dissolution of the saline soil destroy the structure of the soil itself, resulting in an increasing amount of dissolution. Salt expansion and collapse of the soil are irreversible [22].

In the process of multiple freeze-thaw and precipitation cycles, the maximum salt-expansion and frost-heave deformation of sample 1 is $0.125 \mathrm{~mm}$, and when it finally shows settlement deformation, it is $0.63 \mathrm{~mm}$. The maximum saltexpansion and frost-heave deformation of sample 2 is $0.248 \mathrm{~mm}$, and its final settlement deformation is $0.118 \mathrm{~mm}$. The salt-expansion and frost-heave deformation of the highsalt soil is 1.98 times that of the low-salt body, whereas the settlement deformation of the low-salt soil is 5.3 times that of the high-salt body. It can be seen that the precipitation mainly affects the collapsibility deformation of the soil, but the impact on the salt-expansion and frost-heave deformation is not significant.

\section{Estimation of Subgrade Deformation in DY High-Speed Railway Test Section}

According to the formula for calculating the salt-expansion ratio of GB/T50942-2014 [18] and the "Technical Guidelines for Highway Design and Construction in the Saline Soil Regions" [23], combined with the results of laboratory tests, the following equation can be used to estimate the saltexpansion rate of the DY high-speed railway subgrade with coarse-grained saline soil:

$$
\bar{\eta}=\frac{\Delta h}{H} \times 100 \%,
$$

where $\bar{\eta}$ is the average salt-expansion rate, $\Delta h$ is the maximum salt-expansion and frost-heave deformation that 
TABLE 3: Salt-expansion rate of saline soil with different salt contents.

\begin{tabular}{lccc}
\hline Salt content $(\%)$ & $\begin{array}{c}\text { Maximum salt-expansion and frost-heave } \\
\text { deformation }(\mathrm{mm})\end{array}$ & $\begin{array}{c}\text { Sensitive depth (mm) } \\
\text { Salt-expansion ratio (\%) }\end{array}$ & 0.25 \\
3.5 & 0.125 & 50 & 0.496 \\
\hline
\end{tabular}

TABLE 4: Estimation results of the salt-expansion amount.

\begin{tabular}{lccccc}
\hline Salt content $(\%)$ & $\begin{array}{c}\text { Salt-expansion } \\
\text { ratio }(\%)\end{array}$ & $\begin{array}{c}\text { Sensitive } \\
\text { depth }(\mathrm{cm})\end{array}$ & $\begin{array}{c}\text { Maximum } \\
\text { deformation }(\mathrm{mm})\end{array}$ & $\begin{array}{c}\text { Allowable postconstruction } \\
\text { deformation }(\mathrm{cm})\end{array}$ & $\begin{array}{c}\text { Beyond the } \\
\text { standard? }\end{array}$ \\
\hline 1.5 & 0.25 & 50 & 1.25 & 5 & No \\
3 & 0.496 & 50 & 2.48 & 5 & No \\
\hline
\end{tabular}

TABLE 5: Dissolution ratio of saline soil with different salt contents.

\begin{tabular}{lccc}
\hline Salt content $(\%)$ & Maximum dissolution deformation $(\mathrm{mm})$ & Sensitive depth $(\mathrm{mm})$ & Dissolution ratio $(\%)$ \\
\hline 1.5 & 0.63 & 50 & 1.26 \\
3 & 0.118 & 50 & 0.236 \\
\hline
\end{tabular}

TABle 6: Estimation results of the dissolved settlement.

\begin{tabular}{lccccc}
\hline Salt content (\%) & $\begin{array}{c}\text { Dissolution } \\
\text { ratio }(\%)\end{array}$ & $\begin{array}{c}\text { Sensitive } \\
\text { depth }(\mathrm{cm})\end{array}$ & $\begin{array}{c}\text { Maximum } \\
\text { deformation }(\mathrm{mm})\end{array}$ & $\begin{array}{c}\text { Allowable postconstruction } \\
\text { deformation }(\mathrm{cm})\end{array}$ & $\begin{array}{c}\text { Beyond the } \\
\text { standard? }\end{array}$ \\
\hline 1.5 & 1.26 & 50 & 6.3 & 5 & No \\
3 & 0.236 & 50 & 1.18 & 5 & No \\
\hline
\end{tabular}

occurred during freeze-thaw and precipitation cycles, and $H$ is the sensitive depth affected by temperature in the test.

According to the results of laboratory tests, the deformation sensitivity depth and the maximum salt-expansion and frost-heave deformation of the soil under the working condition can be obtained, and the salt-expansion rate is obtained. It can be determined from the above results that the sensitive depth of soil salt-expansion and frost-heave deformation affected by temperature is between $0 \mathrm{~cm}$ and $20 \mathrm{~cm}$. Because the entire deformation amount is small under this condition, $5 \mathrm{~cm}$ can be used as the sensitive depth of deformation, and the calculated salt-expansion rate is large and partial. The salt-expansion ratios of saline soils with different salt contents are summarised in Table 3.

According to the monitoring results of the ground temperature on-site, the lowest temperature is about $5^{\circ} \mathrm{C}$ at a depth of $50 \mathrm{~cm}$, which can be used as the salt-expansion sensitive depth. According to equation (1), the maximum deformation amount of the subgrade test section can be estimated, as shown in Table 4. Using the salt-expansion rate obtained in the laboratory test estimates the deformation of the subgrade. When the salt content is $1.5 \%$, the maximum salt-expansion and frost-heave deformation of the site subgrade is $1.25 \mathrm{~mm}$. When the salt content is $3 \%$, the maximum salt-expansion and frost-heave deformation of the site subgrade is $2.48 \mathrm{~mm}$.

Similarly, the dissolution rate of the saline soil with different salt contents and estimation of the dissolved settlement are summarised in Tables 5 and 6, respectively. From Tables 4 and 6 , it is seen that the maximum salt expansion, frost-heave deformation, and dissolved settlement of the two kinds of soil samples are less than $5 \mathrm{~cm}$, which is in line with TB10621-2014 [18]. Therefore, coarse saline soil can be used as the roadbase filler.

\section{Conclusions}

Because temperature is a key factor affecting the deformation of saline soil, the temperature of coarse-grained saline soil along the DY high-speed rail is first monitored onsite. Through the monitoring results, the temperature variation law of the coarse-grained saline soil was obtained, and the position of the constant-temperature layer was determined. The temperature in the soil changes as the ambient temperature changes. As the depth increases, there will be some lag in temperature changes, and the magnitude of the change will become increasingly smaller. When a certain depth is reached, the temperature is basically no longer affected by the external environment. Moreover, because the upper layer of soil exerts a similar thermal insulation effect, the temperature of the lower soil is often higher than that of the upper soil. Then, combined with previous research results, a new freeze-thaw cycle test that considers precipitation was proposed.

It was found that the deformation of saline soil is the result of combined effects of temperature, water, and salt content. Under the freeze-thaw cycles and precipitation conditions, the content of sodium sulphate has a great influence on the moisture content and deformation in coarsegrained saline soil, but the effect on temperature is not obvious. In the test, more water in the high-salt sample was involved in water migration, so the removal and addition of 
water in the soil are timelier. The moisture content changes are more concentrated when the external environment changes for high-salinity soil. Although the sample will produce a large amount of salt-expansion and frost-heave deformation during the cooling phase of each cycle, this will disappear after heating and eventually exhibit dissolved settlement. Moreover, the dissolved settlement will increase as the test progresses. Therefore, precipitation is the main reason for dissolved settlement deformation.

Finally, through calculation, the dissolved settlement of coarse-grained saline soil is predicted, as well as the saltexpansion and frost-heave deformation. It was confirmed that coarse-grained saline soil can be used as a filling material for a high-speed railway subgrade.

\section{Data Availability}

The data used to support the findings of this study are available from the corresponding author upon request.

\section{Conflicts of Interest}

The authors declare that there are no conflicts of interest.

\section{Acknowledgments}

This research was supported by the Natural Science Foundation of China (Grant No. 51209006), the Major Scientific Research Project of the China Railway Group (Grant No. 2017-major-11-04), and the Fundamental Research Funds for the Central Universities, CHD (Grant No. 300102219219).

\section{References}

[1] Q. Lv, L. Jiang, B. Ma, B. Zhao, and Z. Huo, "A study on the effect of the salt content on the solidification of sulfate saline soil solidified with an alkali-activated geopolymer," Construction and Building Materials, vol. 176, pp. 68-74, 2018.

[2] X. Wan, Q. Hu, and M. Liao, "Salt crystallization in cold sulfate saline soil," Cold Regions Science and Technology, vol. 137, pp. 36-47, 2017.

[3] H. Liu, F. J. Niu, and Y. H. Niu, "Study of design of filling material and setting anti-frost layer for high-speed railway roadbed in seasonally frozen regions," Chinese Journal of Rock Mechanics and Engineering, vol. 30, pp. 2549-2557, 2011.

[4] X. B. Huang, L. X. Zhou, S. J. He, and H. X. Zhou, "Study on test of saline soil ground treatment with the soaking and dissolving combined dynamic compaction method," Rock and Soil Mechanics, vol. 27, pp. 2080-2084, 2006.

[5] J. P. Gao, J. H. Wu, Y. S. Sheng, and J. C. Wang, "A multifactor study of salt expansion of sulphate salty soil," Journal of Glaciology and Geocryology, vol. 18, no. 2, pp. 170-177, 1996.

[6] P. R. Zhang, X. F. Huang, X. H. Yang, Z. L. Liu, and Z. H. Zhu, "Experiment on coupling effect of water and thermal field and salt-expansion deformation of salty soil," Fundamental Theroy and Experimental Research, vol. 39, no. 5, pp. 1619-1624, 2018.

[7] Q. Wu and Y. Zhu, "Experimental studies on salt expansion for coarse grain soil under constant temperature," Cold Regions Science and Technology, vol. 34, no. 2, pp. 59-65, 2002.

[8] C. Wang, Y. Lai, M. Zhang, and S. Li, "A generalized thermal conductivity model of geomaterials based on micro-structures," Acta Geotechnica, pp. 1-14, 2018.
[9] Y. Lai, D. Wu, and M. Zhang, "Crystallization deformation of a saline soil during freezing and thawing processes," Applied Thermal Engineering, vol. 120, pp. 463-473, 2017.

[10] S. S. Zhang, X. H. Yang, and Q. M. Zhang, "Large-scale model tests on embankment of crude coarse grained saline soil," Chinese Journal of Geotechnical Engineering, vol. 34, pp. 842-847, 2012.

[11] Z. A. Xiao, Y. M. Lai, and Z. M. You, "Experimental study on impact of salt content on deformation characteristics of sodium sulfate soil under freeze-thaw conditions," Chinese Journal of Geotechnical Engineering, vol. 39, pp. 953-960, 2017, in Chinese.

[12] S. S. Zhang, X. H. Yang, and Z. R. Dai, "Freezing-thawing cycles and salt expansion test of crude coarse grain clay salty soil," China Journal of Highway and Transport, vol. 22, pp. 28-32, 2009.

[13] M. Zhang, X. Zhang, Y. Lai, J. Lu, and C. Wang, "Variations of the temperatures and volumetric unfrozen water contents of fine-grained soils during a freezing-thawing process," Acta Geotechnica, pp. 1-7, 2018.

[14] Z. Liu, J. Liu, X. Li, and J. Fang, "Experimental study on the volume and strength change of an unsaturated silty clay upon freezing," Cold Regions Science and Technology, vol. 157, pp. 1-12, 2019.

[15] S. S. Zhang, Study on the Characteristic of the Coarse Grain Clay Sulfate Salty Soil, Thesis, Chang'an University, Xi'an, China, 2007, in Chinese.

[16] Y. S. Deng, P. He, and C. L. Zhou, "An experimental research on the thermal conductivity coefficient of saline soil," Journal of Glaciology and Geocryology, vol. 26, pp. 319-323, 2004, in Chinese.

[17] TB 10102-2010, Industry Standard of the People's Republic of China, Code for Soil Test of Railway Engineering, Chinese Railway Publishing House, Beijing, China, 2010.

[18] GB/T50942-2014, National Standard of the People's Republic of China, Technical Code for Building in Saline Soil Regions, China Architecture \& Building Press, Beijing, China, 2014.

[19] TB 10621-2014, National Standard of the People's Republic of China, Code for Design of High Speed Railway, Chinese Railway Publishing House, Beijing, China, 2014.

[20] J. Fang, X. Li, J. Liu, C. Liu, Z. Liu, and Y. Ji, "The crystallization and salt expansion characteristics of a silty clay," Cold Regions Science and Technology, vol. 154, pp. 63-73, 2018.

[21] Y. S. Deng, P. He, C. L. Zhou et al., "Experimental study of permeability coefficient of saline soils," Journal of Glaciology and Geocryology, vol. 28, pp. 772-775, 2006.

[22] W. X. Bao, X. H. Yang, and Y. L. Xie, "Research on salt expansion of representative crude saline soil under freezing and thawing cycles," Chinese Journal of Geotechnical Engineering, vol. 28, pp. 1991-1995, 2006, in Chinese.

[23] Xinjiang Highway Society, Technical Guidelines for Highway Design and Construction in the Saline Soil Regions, China Communication Press, Beijing, China, 2006. 


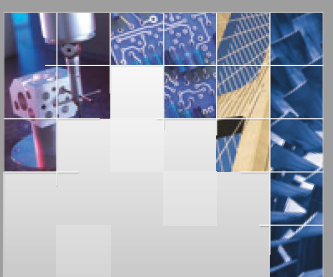

\section{Enfincering}
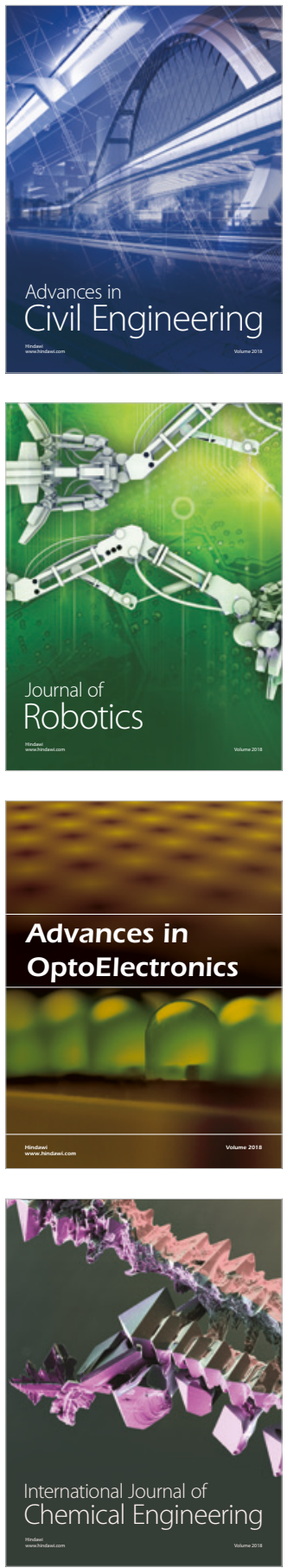

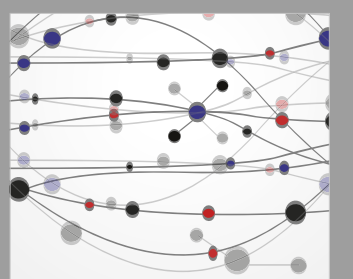

\section{Rotating \\ Machinery}

The Scientific World Journal

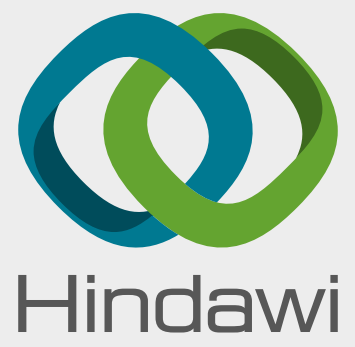

Submit your manuscripts at

www.hindawi.com
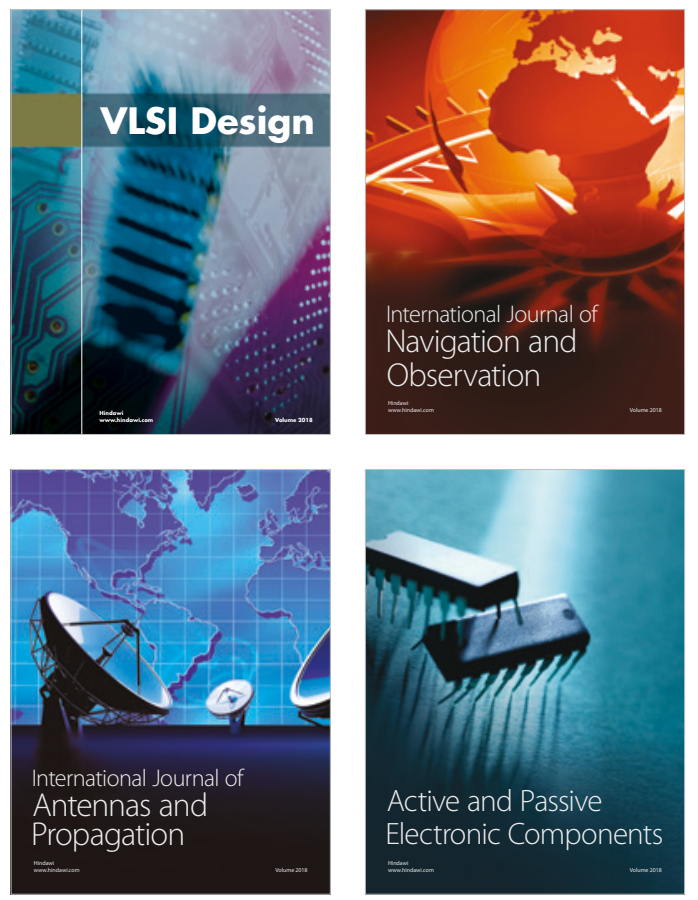
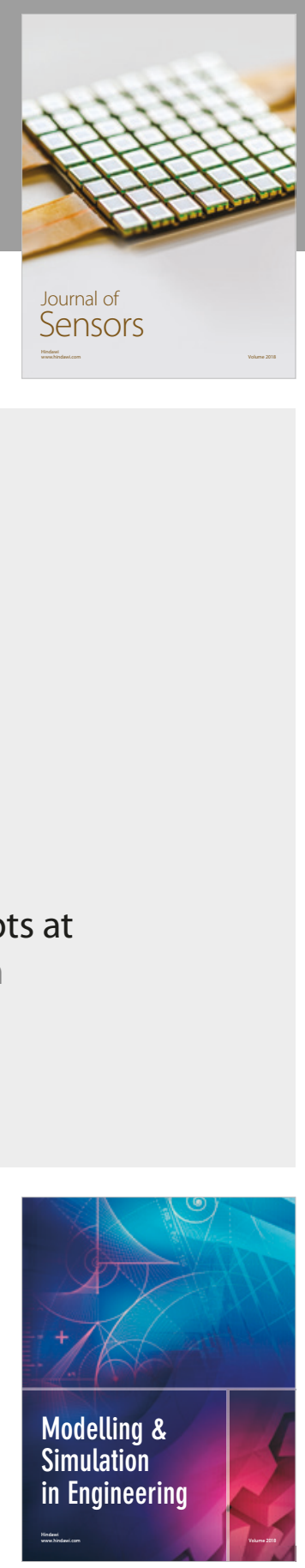

\section{Advances \\ Multimedia}
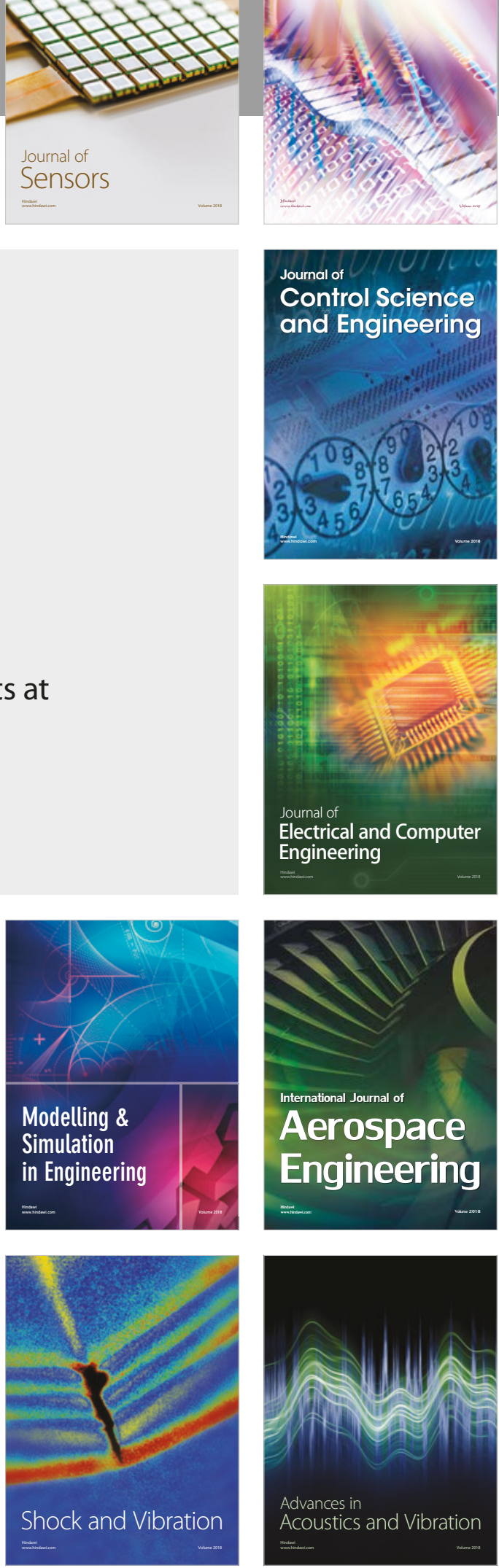